\title{
Single Incision Modified Jones Transfer for Radial Nerve Paralysis: An Aesthetic Alternative
}

\author{
Ravikiran Naalla ${ }^{1} \quad$ Maneesh Singhal ${ }^{1}$ \\ ${ }^{1}$ Department of Plastic Reconstructive and Burns Surgery, All India \\ Institute of Medical Sciences, New Delhi, India
}

Indian J Plast Surg:2020;53:452-453

Various modifications have been described for the classic Jones transfer (Starr, Brand and Boyes). All of these techniques require multiple incisions over the dorsal and volar aspects of the forearm. These time-tested procedures are known for good results, but the cosmesis is unacceptable for some patients. Single incision technique is a simpler alternative for achieving better aesthetic results. Although this technique ${ }^{1}$ was described more than a decade ago, we feel it is underused. The aim of this article is to highlight the distinct advantages of the single incision technique over the conventional technique.

Four patients underwent single incision modified Jones transfer for radial nerve palsy. Three of the four patients had posttraumatic radial nerve palsy and one had sequalae of brachial plexus palsy. Flexor carpi radialis (FCR)-based tendon transfer was done in all patients. Incision was marked over the radial aspect of the forearm, extending from the junction of the upper and middle thirds of the forearm to just proximal to the radial styloid process and then curved toward the Lister tubercle. Through this incision, all the donor and recipient tendons were dissected. The pronator teres (PT) with a $2 \mathrm{~cm}$ periosteal sleeve was dissected to reach the musculotendinous junction of the extensor carpi radialis brevis. The FCR and palmaris longus (PL) were transected at the wrist level and dissected proximally. The extensor pollicis longus (EPL) was rerouted to the radial side of the Lister tubercle after dividing at the musculotendinous

published online July 17,2020
DOI https://doi.org/

10.1055/s-0040-1714183

ISSN 0970-0358.
Address for correspondence Maneesh Singhal, MS, MCh, FRCS (Glasg), Department of Plastic Reconstructive and Burns Surgery, All India Institute of Medical Sciences, Plastic Surgery Office, 5th Floor, Teaching Block, New Delhi, India (e-mail: drmaneesh@gmail.com).

junction. The tendon anastomosis was performed under appropriate tension in a sequential manner (pronator teres [PT] to extensor carpi radialis brevis [ECRB], FCR to extensor digitorum communis [EDC], and PL to extensor pollicis longus [EPL]). There was minor wound dehiscence in the distal suture line which healed spontaneously. Postoperatively, the patient was given above elbow splint with forearm in pronation, wrist in 45 degrees of extension, metacarpophalangeal joints in 30-degree flexion, and thumb in maximus abduction for 4 weeks, followed by monitored physiotherapy. For next 4 weeks, a below elbow night splint was used in the night. The mean follow-up duration was 10.2 months (range: 6-16 months). Three of the four patients had excellent and one had had good outcome based on the Bincaz score. ${ }^{2}$ In this technique, the FCR has to transverse across the scar and this could affect the gliding. None of our patients had this complication due to strict adherence to physiotherapy. Two of the patients had mild wound dehiscence at the suture line which healed spontaneously. Although the single scar is comparatively longer than the scars in conventional technique, it is concealed in most of the day today activities when compared with the dorsal and ventral forearm scars (-Figs. 1 and 2). The advantage of the long incision is a wider exposure facilitating dissection, identification of tendons, and suturing and balancing the tension. Therefore, the procedure is fast and less tedious. (c) 2020. Association of Plastic Surgeons of India.

This is an open access article published by Thieme under the terms of the Creative Commons Attribution-NonDerivative-NonCommercial-License, permitting copying and reproduction so long as the original work is given appropriate credit. Contents may not be used for commercial purposes, or adapted, remixed, transformed or built upon. (https://creativecommons.org/licenses/by-nc-nd/4.0/) Thieme Medical and Scientific Publishers Pvt. Ltd., A-12, 2nd Floor, Sector 2, Noida-201301 UP, India 


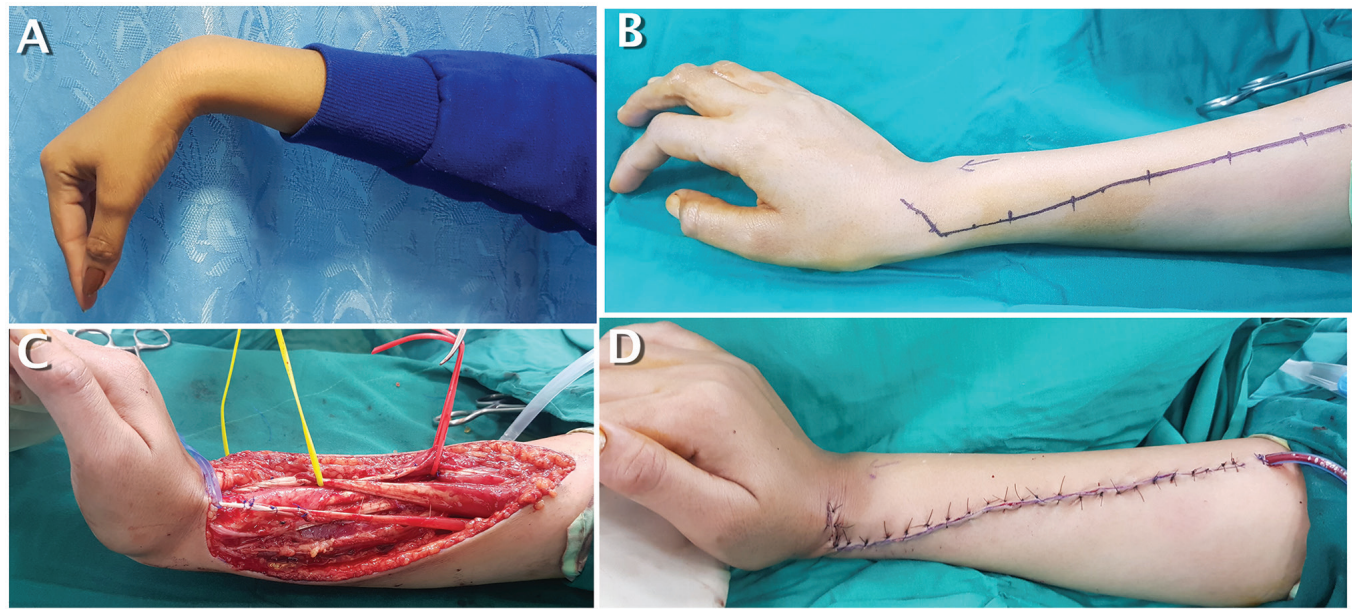

Fig. 1 Image showing (A) wrist, finger and thumb drop, (B) incision marking, (C) PT to ECRB, FCR to EDC, and PL to EPL tendon anastomosis, (D) sutured wound. Abbreviations: ECRB, extensor carpi radialis brevis; EDC, extensor digitorum communis; EPL, extensor pollicis longus; FCR, flexor carpi radialis; PL, palmaris longus; PT, pronator teres.
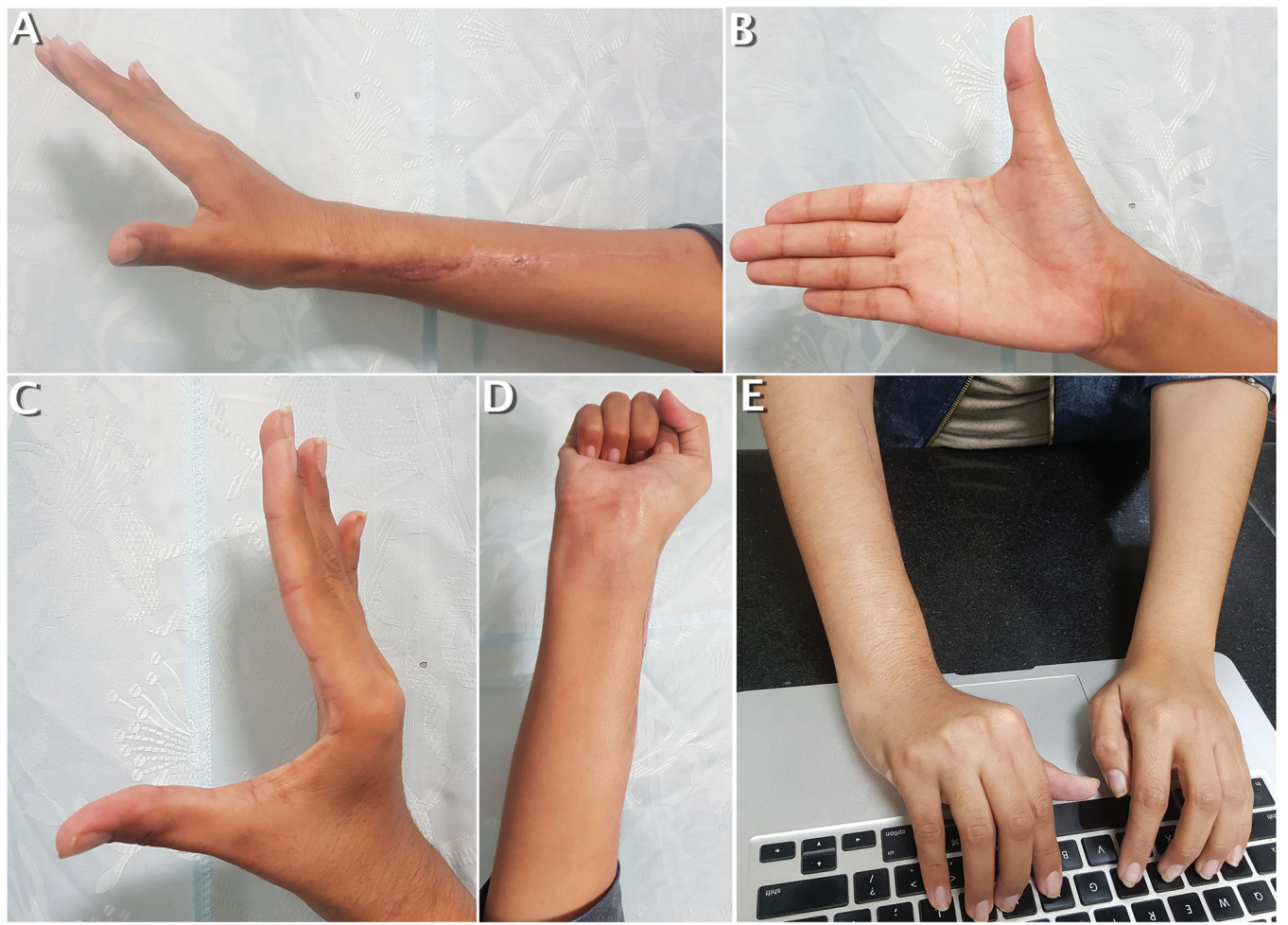

Fig. 2 Image showing postoperative outcome (A) good wrist and finger extension, (B, C) radial and palmar thumb abduction (D, E), and scarless ventral and dorsal surface of forearm.

\section{Financial Disclosures}

None.

\section{Conflict of Interest}

None.

\section{References}

1 Chandraprakasam T, Gavaskar AS, Prabhakaran T. Modified Jones transfer for radial nerve palsy using a single incision: surgical technique. Tech Hand Up Extrem Surg 2009;13(1):16-18

2 Bhardwaj P, Muddappa PP, Bindesh D, Sabapathy SR. Evaluation of extensor pollicis brevis as a recipient of tendon transfer for thumb extension. Indian J Plast Surg 2019;52(2):171-177 